\title{
The history of quality and safety of the surgical patient: from the initial standards to the present day
}

\section{Evolução da história da qualidade e segurança do paciente cirúrgico: desde os padrões iniciais até aos dias de hoje}

Flavio Tomasich, tCbC-PR; André Vinícius de Oliveira²; Annelise de Jesus Oliveiraz; Maria Isabel Toulson Davisson Correia, TCBC-MG ${ }^{3}$ D.

\begin{abstract}
A B S T R A C T
There are currently various concepts related to quality, which have been implemented by many hospitals and other healthcare institutions. The search for continuous improvement, the implementation of a quality culture and hospital accreditation have also been common, in these institutions. However, the history of hospital audits and accreditation is complex and full of dynamic concepts. The American College of Surgeons was pioneer in publishing, more than a century ago, the first document pertaining quality standards. After that, various programs and concepts have been developed and remodeled by distinct entities. In this article, we briefly review the history of quality in the world and Brazil. We also discuss related concepts regarding its assessment in healthcare.
\end{abstract}

Keywords: Accreditation. Health Care Quality. Health Care Quality, Access, and Evaluation. Hospital Accreditation.

\section{THE CONCEPT OF QUAUTY IN HEALTHCARE}

$\mathrm{C}_{\mathrm{it}}^{\mathrm{u}}$ uality is a Latin derived word, and in Portuguese, it has several definitions, among them "degree of perfection, precision or conformity to a certain standard". The perception of quality is different from individual to individual. Throughout human history, several precision measures have been defined so that quality can be characterized ${ }^{1}$. Nonetheless, it was only after the industrial revolution, between 1760 and 1840, and with the growth of mass production, that the need for standardization of the industrial production was perceived ${ }^{2}$. It took several more years for the first "National Standards Bodies" to emerge, which was later translated into the "British Standards Institution", in England and the "National Bureau of Standards" in the United States, both in $1901^{3}$. These organizations have been modernized with the evolution of the industry, and are responsible for several quality implementation programs today, not only in the production area but also in other industry sectors. Years later, in the middle of the 20th century, quality was further tackled by the Asian Tigers as part of the international industrial scenario ${ }^{4}$. In the meantime, the healthcare business has also taken part in the quality movement with programs that have led to the development of the accreditation concept.

Accreditation consists of an evaluation method that aims at gradually increasing the quality of a healthcare institution and the provided assistance ${ }^{5}$. It is the recognition by external and independent peers ${ }^{6}$ for the excellency in standardized criteria ${ }^{7}$. The aim of accreditation programs is continuing education and not inspection ${ }^{8}$ or punishment ${ }^{9}$. There are programs in more than 90 countries $^{10}$, each adapted to the reality for which it operates ${ }^{7}$.

\section{THE HEALTHCARE ACCREDITATION CONCEPT}

O The concept of accreditation has evolved with the history of hospital assessments, which started with the minimum standards of the "American College of Surgeons" (ACS) ${ }^{11}$, in 1918 (Figure 1). It is currently

1 - Universidade Federal do Paraná, Departamento de Cirurgia - Curitiba - PR - Brasil 2 - Universidade Federal do Paraná, Curso de Medicina - Curitiba - PR - Brasil 3 - Universidade Federal de Minas Gerais, Departamento de Cirurgia - Belo Horizonte - MG - Brasil 
related to safe practices and quality healthcare ${ }^{7}$ that promotes trust in the provided services ${ }^{12}$, and it is backed up by the external evaluation of the establishment ${ }^{6}$. Hospitals that seek to obtain certificates provided by accreditation bodies show commitment to safety, efficiency and responsibility ${ }^{13}$. Accreditation programs encourage the implementation of ideal healthcare management practices $^{14}$, which are related to the improvement of the service and its quality, resulting in greater satisfaction ${ }^{15}$ and safety ${ }^{16}$ for the attended patients.

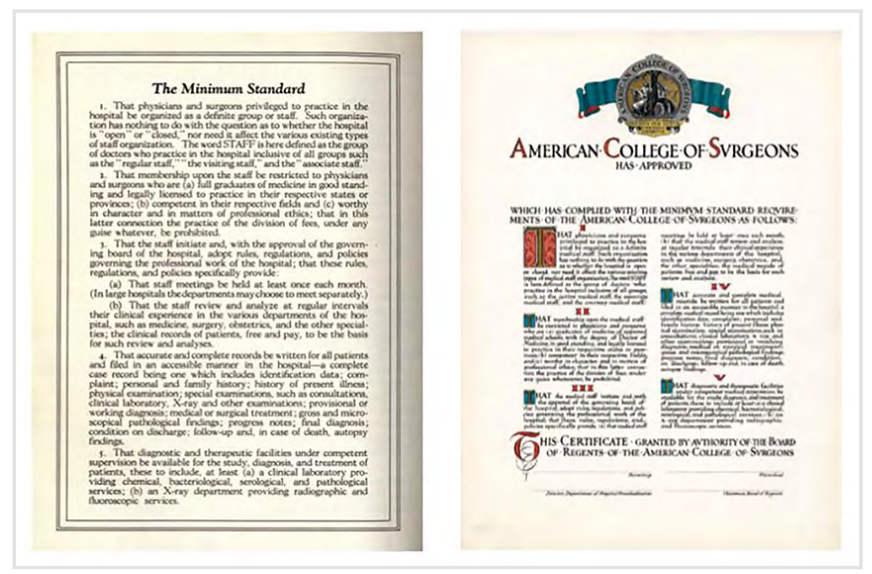

Figure 1. An example of the ACS certificate that was awarded to the hospitals following the minimum healthcare quality patterns, according to the College. (reproduction with permission granted by the ACS).

The implementation of the quality culture in a healthcare institution depends on the joint and synergistic work of the administration and the clinical care team. Only then, can quality be followed on a daily basis ${ }^{17}$

It is important to highlight that certification should not be the objective of the hospital that decides to undergo the accreditation process, but rather, the implementation of a quality culture ${ }^{18}$.

\section{THE HISTORY OF HEALTHCARE QUALITY}

The idea of quality in healthcare permeates treaties of ancient civilizations. It was initially mentioned in the code of Hammurabi, in Babylon, and in the writings of Hippocrates ${ }^{19}$. Although not a new topic, the initial efforts were fragmented and not correlated ${ }^{20}$.
Some authors mention Florence Nightingale's efforts, an English nurse, working in the Crimea was, as the first organizational exercise in healthcare quality, starting in 1854. Nightingale was responsible for reducing the mortality rate among English soldiers from $42.2 \%$ to $2.2 \%$, in six months. The lessons of the Crimean War were an example for Clara Barton, founder of the American Red Cross, during the American Civil War, to try to offer minimal care conditions for the Union soldiers. Joseph Lister is another personality that deserves mentioning, since he inserted antisepsis practices in his daily life. Lister published relevant results in 1867 on the use of carbolic acid and the prevention of infections in healthcare, a topic that still has important impact, today. Moving forward in history, in 1918, with the pandemic of the so-called Spanish flu, another personality that stood out was Rupert Blue, a doctor who presented the ideas on pandemic control, which are still used nowadays ${ }^{20}$.

Before any accreditation program was created, the idea of systematizing medical quality had previously been presented by an American surgeon - Ernest $A$. Codman"2. Codman presented the topic to the "Clinical Congress of Surgeons of North America", in 1912. In the congress, the "Committee on the Standardization of Surgery" was constituted, and became the ACS accreditation organizing committee ${ }^{22}$, officially constituted in 1913, in Chicago ${ }^{11}$.

The "Standard of Efficiency", is a document published in 1918, by the ACS, which is the prototype of hospital accreditation programs ${ }^{11}$ (Figure 1). Since then, the number of programs has increased exponentially ${ }^{6}$. This document was the basis for a field study, carried out in 1919, which evaluated 692 American hospitals with more than 100 beds. Alarming results were identified, as only $13 \%$ of hospitals reached the standards described in the document ${ }^{11}$. Such numbers caused an uproar in the medical community, raising problems to large American hospitals and leading to changes in the attitudes of institutions that had initially failed. Such initiative led to the restructuring of the entire assistance system, which is still seen up to now ${ }^{11}$.

The "Standard of Efficiency" is the cornerstone of hospital accreditation and takes into account basic aspects that are still a reality in hospitals today: proper organization of the medical staff; correct filling of medical records and; availability of diagnostic and therapeutic 
resources ${ }^{23}$. In 1924, the ACS published the hospital standardization program, a document that defended the same principles, and it the precursor of the concepts of quality and safety ${ }^{24}$.

In 1950, with the increase demand for hospital evaluations (in that year, 3290 institutions had been approved) and the need to verify non-surgical structures, the ACS started to require the support from other national professional entities to develop the assessment activities. The "American College of Physicians", the "American Hospital Association", the "American Medical Association" and the "Canadian Medical Association" joined the ACS, and formed, in 195125, the "Joint Commission of Accreditation of Hospitals"(JCAH). Since then, the "Standard of Efficiency" has been renamed the "Hospital Accreditation Program".

Also, in the 50 s of the last century, more specifically in 1958, in parallel with the United States movement, another accreditation program was organized in Canada, which still exists nowadays, entitled "Accreditation Canada". This Canadian body is the second to carry out accreditation in the world ${ }^{25}$.

In 1966, the "Hospital Accreditation Program" was revised and started to demand not only the minimum requirements for the offered services, but also to request the optimal requirements for healthcare treatments. This decision was driven by the fact that many hospitals had already met the minimum requirements and were no longer challenged to improve services. Another important factor, for this review, was the fact that the American government started to require minimum quality of care in the "Medicare" system, forcing the JCAH to tackle a movement which stimulated the improvement above that demanded by the government ${ }^{11}$.

JCAH's accreditation expertise started to be used in the creation of programs in other healthcare areas, such as long-term care institutions (1965), care for the disabled (1969), psychiatric institutions (1970), outpatient care (1975) and palliative care (1983) ${ }^{11}$.

Another major change in the JCAH assessment method took place in 1979, with the development of a new quality assessment standard. The numerical assessment was abolished, and guidance was given to the hospitals to develop a program that integrated all quality assessment activities $^{11}$.
From the 1980s onwards, accreditation programs began to be adopted outside the United States, initially covering other English-speaking countries and later, Latin America and Asian countries ${ }^{24}$.

In 1987, the JCAH once again changed its name to the "Joint Commission on Accreditation of Healthcare Organization" (JCAHO) ${ }^{25}$. In 2003, the item on patient safety was included in the JCAHO documents, with the aim of reducing medical errors, especially those that result in death ${ }^{5}$. Currently, the JCAHO operates in more than 60 countries ${ }^{26}$.

Accreditation Canada, which has also evolved over the years, launched in 2008 a new accreditation program called "Qmentum". The latter revolutionized the organization by combining a clinical assessment tool with a structural assessment. Thus, "Accreditation Canada" assesses the opinion of patients, workers, leaders and shareholders to certify a hospital ${ }^{25}$.

\section{THE HISTORY OF HEALTHCARE QUALITY,}

\section{IN BRAZIL}

In Brazil, the history of hospital evaluation begins with the incipient Hospital Survey Form, in 1935. This document included nine evaluation items, authored by the Hospital Assistance Commission of the Ministry of Health (currently extinct) ${ }^{23}$.

In 1941, the Hospital Organization Division, an active arm of the then Ministry of Education and Health, created rules for the installation, organization and operation of hospitals ${ }^{27}$

In the sixties of the last century, the Institute of Pensions and Retirements of Social Security defined what would be the Hospital Classification Report (ReClar). This had 333 items divided into three areas (physical plant, equipment and organization)23. For a long time, the ReClar was the "accreditation" document used in Brazil $^{28}$. Subsequently, in the 1970s, the Ministry of Health published a series of ordinances in order to improve quality in the healthcare system ${ }^{28}$.

In 1987, the Pan American Health Organization (PAHO), through the Technical Institute for the Accreditation of Health Establishments, tackles the creation of the "Accreditation Manual"12. This document, which has a series of necessary conditions for a hospital to be accredited, 
came into practice in $1989^{24}$. It defines two objectives: to improve hospital services and to have parameters to generate improvements ${ }^{29}$. In 1989, the "Commitment to Hospital Quality" was created, a document was produced by the São Paulo Medical Association and the São Paulo Regional Medicine Council. This was essentially a manual for hospital accreditation in the state of São Paulo. This manual was subsequently the cornerstone for the development of the "National Quality Award"5. Five years later, the Ministry of Health implemented the "Quality Program", and simultaneouslyt created the "National Commission for Quality and Productivity in Health", both with the objective of encouraging the adoption of the quality culture in the country ${ }^{24}$.

In 1997, the Ministry of Health concatenated specialists to organize the "Brazilian model" of accreditation, which in 1998 was translated into the document the "Brazilian Manual of Hospital Accreditation"29. Still in 97, of the last century, the "Brazilian Accreditation Consortium" was created with the objective to assess the education programs of hospitals ${ }^{27}$. In the following year, the "National Accreditation Organization" (ONA) was created, supporting and ratifying what had been written in the manual, in addition to defining the systematic evaluation, elaborating quality standards and training evaluators ${ }^{24}$. In 1999, following the already installed revolution path, the Brazilian Hospital Accreditation Program (PBAH) was created, which is carried out by $\mathrm{ONA}^{24}$. In 2001, the Ministry of Health officialized the ONA as a promoter and guide of the $\mathrm{PBAH}^{19}$.

The ONA promotes the implementation of quality certification for different types of healthcare organizations, including hospitals ${ }^{24}$. In Brazil, as well as in countries like Australia, Canada, the United States of America and Germany ${ }^{17}$, the evaluation process is voluntary and tends to guarantee quality through comparison with standards. The institution's assessment is carried out in terms of infrastructure, processes and results, depending on the level to be implemented ${ }^{24}$. According to the Brazilian model, a hospital can be certified according to three levels of increasing complexity ${ }^{18}$. Level 1 (Accredited) covers essentially security, and checks compliance with technical and structural standards in accordance with the legislation. This level also assesses risk management. Level 2 (Full Accredited) mainly assesses process management and integration. Level 3, on the other hand, focuses on results, and assesses the presence of quality policies and continuous improvement ${ }^{24}$.

\section{THE FUTURE OF HEALTH QUALITY}

The history of accreditation in Brazil is still in development, the cornerstones were imported from international models. However, since the 90s of the last century, national needs have been addressed by the development of new manuals, in order to contemplate Brazilian requirements. Around the world, the idea of implementing the quality culture has reached other levels of care, such as primary care ${ }^{15}$. Considering that in Brazil, the gateway to the Unified Health System (SUS) is the primary care health unit (UBS), this movement has also evolved towards accreditation of this scenario.

The questioning regarding the real role of certifications to the improvement of the quality for patient care and treatment is recurrent in the literature. This is due to the absence of an ideal parameter to measure such data. Observational studies $^{10,26}$, systematic reviews ${ }^{6}$ and prospective studies ${ }^{14}$ have been carried out to try to assess this role, and the results are conflicting. However, even with the lack of consensus, there is a certainty: the evaluation processes and certifications promote the habit of quality in the hospital environment ${ }^{30}$. In other words, they establish attitudes and processes that reduce errors and standardize decision-making, thus decreasing room for failures ${ }^{31}$. Morbidity and mortality costs, in addition to those related to the poor healthcare quality are not acceptable, under the current health management scenario ${ }^{25,30}$. Hospital certifications will not be replaced anytime soon, but they should offer new insights on quality of care so that the differences between accredited and nonaccredited institutions are more measurable ${ }^{25,30}$.

Finally, it is necessary to allude to the new chapter on healthcare quality that is currently being written, the formulation and application of certifications in the area of primary healthcare (PHC), reaching the UBSs, in Brazil. This is a trend that has been seen elsewhere in the world ${ }^{15,32}$.

In Brazil, the advance of theoretical 
formulations on the evaluation of these units in the last 17 years, and considering the country is one of the biggest systemic experiences in PHC is certainly paramount. The idea of certification and evaluation processes has further impacted the system evolution. In 2011, with the program for improving access and quality (PMAQ), it was necessary to establish an external evaluation institution, which was carried out by 40 universities and the federal research centers. With these efforts, the researchers concluded that in this healthcare scenario and under the constitutional context of the SUS, quality is the breadth of the actions officially planned for each healthcare condition ${ }^{33}$.

Since the creation of the Primary Healthcare Department, on May 17, 2019, the task of monitoring the quality assessment in the primary healthcare scenario has been delegated to the Department of Family Health (DESF). The institutionalization of quality practices in the PHC will potentially tackle good management and adequate organization of the service. Thus, the objectives of each UBS must be fully achieved considering the specific population they cover ${ }^{33}$.

\section{Acknowledgment}

We thank the Department of Surgery at the Federal University of Paraná - UFPR for introducing the topic in our studies and supporting us in the publication. To UFPR, our alma mater.

\title{
R E S U M O
}

\begin{abstract}
Sólidos conceitos de qualidade assistencial são adotados em grandes hospitais e serviços de saúde da atualidade. A busca por melhoria contínua, implementação de cultura de qualidade e obtenção de selos de certificação em qualidade hospitalar é comum em tais instituições. Entretanto, a história da avaliação hospitalar e do processo de certificação é longa e repleta de conceitos dinâmicos. $O$ "American College of Surgeons" foi pioneiro ao publicar há mais de um século o primeiro documento contendo diretrizes sobre padrões de qualidade a serem seguidos. Posteriormente, múltiplos programas e conceitos foram criados e remodelados por distintas entidades. Neste artigo, apresentamos breve revisão da história da qualidade no mundo e no Brasil, além de alguns conceitos relacionados à avaliação da mesma em saúde.
\end{abstract}

Palavras chave: Acreditação. Qualidade da Assistência à Saúde. Qualidade, Acesso e Avaliação da Assistência à Saúde. Acreditação Hospitalar.

\section{REFERÊNCIAS}

1. Chandrupatla TR. Quality and reliability in engineering. New York: Cambridge University Press; 2009.

2. Edith IN, Ochubiojo EM. Food quality control: history, present and future. In: Valdez B. Scientific, Health and Social Aspects of the Food Industry. London: IntechOpen; 2012. p. 421-38

3. Olshan MA. Standards making organizations and the rationalization of the american life. Sociol Q. 1993;34(2):319-35.

4. Oliveira JLC, Matsuda LM. Descredenciamento da certificação pela acreditação hospitalar: percepções de profissionais. Texto Contexto Enferm. 2016;25(1):1-8.
5. Novaes HM. O processo de acreditação nos serviços de saúde. Rev Adm Saúde. 2007;9(37):133-40.

6. Brubbak K, Vist GE, Bukholm G, Barach P, Tjomsland $A$. systematic review of hospital accreditation: the challenges of measuring complex intervention effects. BMC Health Serv Res. 2015;15:280.

7. Tabrizi JS, Gharibi F. Primary healthcare accreditation standards: a systematic review. Int J Health Care Qual Assur. 2019;32(2):31020.

8. Caldana G, Gabriel CS. Avaliação do programa de acreditação hospitalar validação de face e conteúdo. Rev Bras Enferm. 2017;70(1):47-53.

9. Fogh $\mathrm{SE}$, Pope $\mathrm{CH}$, Rosenthal SA, Conway PD, Hulick PR, Johnson JL, et al. American College 
of Radiology (ACR) radiation oncology practice accreditation: a pattern of change. Pract Radiat Oncol. 2016;6(5):e171-e177.

10. Devkaran S, O'farrel PN, Ellahhan S, Arcangel R. Impact of repeated hospital accreditation surveys on quality and reliability, an 8-year interrupted time series analysis. BMJ Open. 2019;9:e024514.

11. Roberts JS, Coale JG, Redman RR. A History of the Joint Commission on Accreditation of Hospitals. JAMA. 1987;258(7):936-40.

12. Novaes HM. História da Acreditação Hospitalar na América Latina - O Caso Brasil. Revista de Administração Hospitalar e Inovação em Saúde. 2015;12(4);49-61.

13. Chazal RA, Houser S. The ACC and AHA: setting a new standard for hospital accreditation - together [editorial]. J Am Coll Cardiol. 2016;68(24):2708-9.

14. Berssaneti FT, Saut AM, Barakat MF, Calarge FA. Existe uma relação entre os programas de acreditação e os modelos de excelência organizacional? Rev EsC Enferm USP. 2016;50(4):648-55.

15. El-jardali $F$, Hemadeh $R$, Jaafar $M$, Sagherian $L$, El-skaff R, Mdeihly $R$, et al. The impact of accreditation of primary healthcare centers: successes, challenges and policy implications as perceived by healthcare providers and directors in Lebanon. BMC Health Serv Res. 2014;14:86.

16. Al Kuwaiti A, Al Muhanna FA. Challenges facing healthcare leadership in attaining accreditation of teaching hospitals. Leadersh Health Serv (Bradf Engl). 2019;32(2):170-81.

17. Camillo NRS, Oliveira JLC, Bellucci Jr. JA, Cervilheri AH, Haddad MCFL, Matsuda LM. Accreditation in a public hospital: perceptions of a multidisciplinary team. Rev Bras Enferm. 2016;69(3):451-9.

18. Oliveira JLC, Gabriel CS, Fertonani HP, Matsuda LM. Mudanças gerenciais resultantes da acreditação hospitalar. Rev. Latino-Am. Enfermagem. 2017;25:e2851.

19. Portela OT, Schmidt AS. Proposta de metodologia de avaliação e diagnóstico de gestão hospitalar. Acta Paul Enferm. 2008;21(spe):198-202.

20. Sheingold $B H$, Hahn JA. The history of healthcare quality: the first 100 years 1860 1960. Int J Africa Nurs Sci. 2014;1:18-22.

21. Fortes MT, Mattos RA, Baptista TWF. Acreditação ou acreditações? Um estudo comparativo entre a acreditação na França, no Reino Unido e na Catalunha. Rev Assoc Med Bras. 2011;57(2): 239-246.

22. Verheyden CN. Medical accreditation in the United States: what for? Plast Reconstr Surg. 2016;138(6):1367-1370.

23. Feldman LB, Gatto MAF, Cunha ICKO. História da evolução da qualidade hospitalar: dos padrões a acreditação. Acta Paul Enferm. 2004;18(2):213-9.

24. Mendes GHS, Mirandola TBS. Acreditação hospitalar como estratégia de melhoria: impacto em seis hospitais acreditados. Gest Prod. 2015;22(3):636-48.

25. Chuang S, Howley PH, Gonzales SS. An international systems-theoretic comparison of hospital accreditation: developing an implementation typology. Int J Qual Health Care. 2019;31(5):371-7.

26. Lam MB, Figueroa JF, Feyman $Y$, Reimold KE, Orav EJ, Jha AK. Association between patient outcomes and accreditation in US hospitals: observational study. BMJ. 2018;363:k4011.

27. Schiesari LMC, Kisil MA. Avaliação da qualidade nos hospitais brasileiros. Rev Adm Saúde. 2003;5(18):7-17.

28. Corrêa JE, Turrioni JB, Mello CHP, Santos ACO, Silva CES, Almeida FA. Development of a system measurement model of the Brazilian hospital accreditation system. Int J Environ Res Public Health. 2018;15(11):2520.

29. Agência Nacional De Vigilância Sanitária (ANVISA). Acreditação: a busca pela qualidade nos serviços de saúde. Rev Saúde Pública. 2004; 38(2):335-6.

30. Jha AK. Accreditation, quality and making hospital better. JAMA. 2018;320(23):2410-1.

31. Bogh SB, Falstie-Jensen AM, Hollnagel E, Holst 
R, Braithwaite J, Johnsen S P. Improvement in quality of hospital care during accreditation: A nationwide stepped-wedge study. Int J Qual Health Care. 2016;28(6):715-20.

32. Programa Nacional de Acreditação em Saúde. Manual de Acreditação de Unidades de

Received in: 01/06/2020

Accepted for publication: 08/06/2020

Conflict of interest: no.

Funding source: none.
Saúde. Lisboa (PT): Direção Geral de Saúde; Departamento de Qualidade na Saúde; 2014. 33. Fachinni LA, Tomasi E, Dilélio AS. Qualidade da atenção primária à saúde no Brasil: avanços, desafio e perspectivas. Saúde Debate. 2018;42(spe 1):208-23.

\section{Mailing address:}

Annelise de Jesus Oliveira

E-mail: nelise8@gmail.com

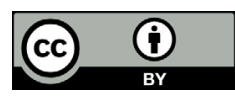

